\title{
EMPIRICAL METHODS FOR ESTIMATING REFERENCE SURFACE NET RADIATION FROM SOLAR RADIATION
}

\author{
Danilton L. Flumignan ${ }^{1 *}$, Maiara K. A. Rezende ${ }^{2}$, Eder Comunello ${ }^{1}$, Carlos R. Fietz ${ }^{1}$
}

1*Corresponding author. Embrapa Agropecuária Oeste/ Dourados - MS, Brasil. Email: danilton.flumignan@embrapa.br

\section{KEYWORDS \\ Weather station, Gauss Method, Practical Method, reference evapotranspiration.}

\begin{abstract}
Net radiation $\left(\mathrm{R}_{\mathrm{n}}\right)$ of reference surface is important information that has many applications, but its measurement is rare due to the high cost of the sensor and the complexity involved on the measurement. Therefore, estimate $R_{n}$ from another variable is desirable, as from solar radiation $\left(\mathrm{R}_{\mathrm{s}}\right)$; however, standard methods used are complex, making interesting the use of simplified methodologies. Considering these aspects, the present study aimed to set two empirical methods to estimate $R_{n}$ from $R_{s}$ for Dourados region, Mato Grosso do Sul, Brazil. One method was based on mathematical modeling (Gauss Method). The other one was a more simplified and practical approach (Practical Method) comprising the determination of fixed monthly conversion factors. It was used daily $R_{s}$ data of a 12-years database. With these, there were estimated $R_{n}$ values by the standard method recommended by FAO. Gauss Method was set using Table Curve 2D 5.01 software. Modeling consisted in defining the values of the equation parameters. On Practical Method, we developed monthly coefficients of the ratio $R_{n} / R_{s}$. In order to validate both methods it was measured $R_{s}$ and $R_{n}$ during two years using high precision sensors. Both estimating methods showed satisfactory results, with relative mean absolute error values lower than $5.8 \%$.
\end{abstract}

\section{INTRODUCTION}

In agrometeorology, reference surface consists of a large grass field, which is under full growth, completely shadowing the ground, with approximately $12 \mathrm{~cm}$ height, maintained without water and soil fertility restrictions, besides of being free of pests, diseases and weeds (Allen et al., 1998).

In tropical countries, this theoretical definition is replicated by grass fields cropped with Paspalum notatum Flügge. This reference surface standardization has great importance in order to ensure the quality of the data obtained, besides of allowing a reliable comparison among different weather stations.

For some applications in agrometeorology and irrigation, measurements of net radiation $\left(\mathrm{R}_{\mathrm{n}}\right)$ from this surface are required. $R_{n}$ corresponds to the difference between the total energy that reaches the surface and the amount that leave it. This difference constitutes the amount of energy that is used by the reference surface, essentially for three processes: evapotranspiration, air and soil warming. For example, one of the most important application of $R_{n}$ relies on its use for estimating the reference surface evapotranspiration $\left(\mathrm{ET}_{\mathrm{o}}\right)$. Nowadays, the main model used to estimate $\mathrm{ET}_{\mathrm{o}}$, known as ASCE Penman-Monteith (Allen et al., 2005), requires $R_{n}$ as an input. In this sense, it is necessary to remember that $\mathrm{ET}_{\mathrm{o}}$ is an important information required in many studies or practical works, such as for rainfed agriculture (definition of best sowing periods and crop zoning) or for irrigated agriculture (design and management of irrigation systems).

Although $R_{n}$ is important information, its measurement on weather stations is rare due to the high cost of the sensor and the complexity involved on the measurement. This complexity can be attributed to errors in sensor operation, but mainly due to the fact that is relatively normal that weather stations do not receive the well-deserved care to ensure the surface can really be considered a reference surface, as demonstrated by Allen (1996) and Allen et al. (2005). If the weather station surface is not managed accordingly to the protocol to match a reference surface, $R_{n}$ data are certainly influenced by this mismanagement, producing $R_{n}$ values that differ from those that should occur in practice. Examples of mismanagement are: lack of grass field irrigation in arid

\footnotetext{
${ }^{1}$ Embrapa Agropecuária Oeste/ Dourados - MS, Brasil. 
regions or during severe dry seasons in humid regions; use of mixed grass species or other different species than Paspalum notatum Flügge; nutritional deficiency; grass field that do not completely shadow the ground or the absence of a grass field (use of bare soil or a cemented floor).

Different alternatives have been applied to allow $R_{n}$ estimation of different surfaces, each one presenting positive or negative characteristics. Sophisticated alternatives allow large area estimates, but it evolves acquisition, treatment, and analyses of satellite images, and consequent application in models such as in the study of Santos et al. (2015). They used MODIS sensor images and the models SEBAL, METRIC and one proposed by Bisht et al. (2005). Bisht \& Bras (2010), also using MODIS sensor, states that the methodology proposed in their study can relies exclusively in remote sensing, when in the absence of ground auxiliary observations.

Considering these difficulties, Allen et al. (2005) recommended $R_{n}$ values required for $E_{0}$ calculation should, preferentially, be estimated from measured solar radiation $\left(\mathrm{R}_{\mathrm{s}}\right)$, accordingly to the methodology described in the document. This is a high-quality method, but it also has a high level of complexity, because requires some astronomic calculations, besides of requiring as input data the geographical coordinates and measured data of air temperature and relative humidity.

The use of empirical methods is an alternative as a practical solution where data are obtained from the systematic observation of the phenomenon under evaluation. These methods have limited validity, been applicable for situations similar where were calibrated, but with satisfactory results when used on these criteria. Its use in other regions can be feasible, since its validity is previously certified.

Conceição (2006), when studying Ilha Solteira region, Brazil, obtained an empirical relation which says that reference surface $R_{n}$ represents $65.3 \%$ of measured $R_{s}$. Heldwein et al. (2012) evaluating potato crop endorsed this perception, by stating that $R_{n}$ of any vegetation can be estimated from $R_{s}$ measurements with good accuracy for modeling purposes. For Piracicaba region, Brazil, Pereira et al. (2007) states that $R_{n}$ of the reference surface can be assessed by a strong relationship between $R_{n}$ and $R_{s}$, being $R_{n} 57.4 \%$ of the $R_{s}$. Sentelhas \& Nascimento (2003), also in Piracicaba, found same strong relationship having a linear dependence and being $\mathrm{R}_{\mathrm{n}}$ equal to $54 \%$ of $\mathrm{R}_{\mathrm{s}}$. These authors also remind there is a seasonal variability in this relationship, considering a maximum value (59.5\%) occurred in February, while a minimum occurred in May $(47.3 \%)$.

Therefore, this study aimed to establish two empirical methods to estimate $R_{n}$ of the reference surface (Paspalum notatum Flügge) from $\mathrm{R}_{\mathrm{s}}$ measurements for the region of Dourados, State of Mato Grosso do Sul, Brazil. One of the methods was set considering a precise purpose (Gauss Method), because it constitutes a mathematical modelling, while the other was set considering a more practical purpose (Practical Method), because it considers the utilization of fixed monthly conversion coefficients.

\section{MATERIAL AND METHODS}

It was considered one weather station of Embrapa Western Agriculture, which is located at Dourados, State of Mato Grosso do Sul, Brazil (latitude of $22^{\circ} 16^{\prime} \mathrm{S}$; longitude of $54^{\circ} 49^{\prime} \mathrm{W}$ and $408 \mathrm{~m}$ of altitude). The weather station was managed accordingly to the protocols (Allen et al., 2005; Allen et al., 1998) that are required to ensure and it can be considered as a reference surface. It is located in an area of 1.4 ha, cropped with Paspalum notatum Flügge grass and positioned in such a way that the shortest distance from the border has $37 \mathrm{~m}$, ensuring the minimization of any problem related to advection, shadowing and windbreak (Figure 1). Grass cover was periodically mowed to keep its height between 9 and 15 $\mathrm{cm}$, besides of adequate crop management and irrigation (when under severe drought), which was done in order to promote no water restriction.

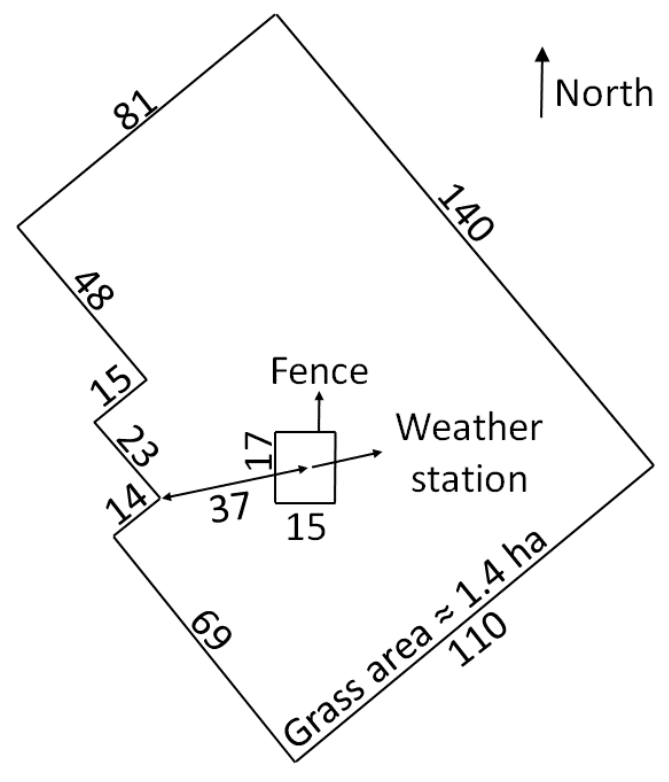

FIGURE 1. Layout of the weather station of Embrapa Western Agriculture located at Dourados, State of Mato Grosso do Sul, Brazil. Dimensions in meters.

According to Kottek et al. (2006), the climate is an equatorial monsoon (Am), being characterized as a transition zone between the equatorial savannah with dry winter (Aw), to the north, and the warm temperate fully humid with hot summer (Cfa), to the south. As a rule, it has hot and rainy summer, while the winter is dry and cold (Fietz \& Fisch, 2008). The Dourados weather station data (EMBRAPA, 2014) for the period of 1980 to 2012 (33 years), presents an average annual precipitation of 1,389 $\mathrm{mm}$, being December the rainiest month, with $178 \mathrm{~mm}$, and July the driest one, with $44 \mathrm{~mm}$. Average annual temperature is $22.5^{\circ} \mathrm{C}$, being July the coldest month (18 $\left.{ }^{\circ} \mathrm{C}\right)$, and December and January the hottest ones $\left(25.4^{\circ} \mathrm{C}\right)$.

The study was divided into two phases: calibration and validation. On the calibration phase, daily $R_{\mathrm{S}}$ data of 12 consecutive years were used (01/01/2001 to $12 / 31 / 2012$ ). Database is almost free of missing data and it presents $99.5 \%$ of the data for this period. All $R_{s}$ data were previously scrutinized regarding its quality, according to Allen (1996) and Allen et al. (2005) criteria.

$R_{n}$ values were estimated accordingly to the standardization presented in ASCE-EWRI (2005). In addition to the $R_{s}$, it was also necessary to use air temperature and relative humidity measurements, and 
these data were obtained from the same weather station and same period.

Calibration procedure consisted of defining two methods (Gauss Method and Practical Method) by analyzing the relation that exists between the $R_{s}$ and the $R_{n}$ values, it mean, the ratio $R_{n} / R_{s}$ in $\%$. For example, a relation of $60 \%$ for a day or a month indicates from the total energy that reached surface $\left(R_{s}\right), 60 \%$ was used by the surface for its different process $\left(R_{n}\right)$.

The Gauss equation (Equation 1) coefficients were calibrated using the software Table Curve 2D 5.01; and the mathematical model is described as follow:

$$
y=a+b \times e^{-0.5 \times\left(\frac{x-c}{d}\right)^{2}}
$$

being,

$y$ - variable to be predicted;

$a, b, c$ and $d$ - equation coefficients to be set, and

$x$ - predictor variable.

Modeling was done in such way to establish a $y$ value, which corresponds to the relation $\mathrm{R}_{\mathrm{n}} / \mathrm{R}_{\mathrm{s}}$, for every $x$ value that corresponds to the day of the year (day 1 to day 366 in leap year). Therefore, modeling work consisted in setting the values of the coefficients $a ; b ; c$ and $d$ of the Equation 1 that best fit the relation between $y$ and $x$.

On the other hand, fixed monthly coefficients of the ratio $R_{n} / R_{s}$, instead of daily, were determined for the Practical Method, requiring no mathematical modelling. This was achieved through a simple calculation of the mean values for each month of the year.

In order to represent each of the 366 days in the Gauss Method case, or each of the 12 months in the Practical Method case, mean values of all 12 years were used.
Validation of both models consisted in analyze the quality of $R_{n}$ estimates obtained from the Gauss and Practical Methods, using as input daily measurements of $\mathrm{R}_{\mathrm{s}}$. Therefore, we used $\mathrm{R}_{\mathrm{s}}$ measurements obtained by a high precision sensor (pyranometer CMP3 of Kipp \& Zonen $\left.{ }^{\circledR}\right)$. This sensor was installed on the Dourados weather station during two years $(07 / 01 / 2013$ to $06 / 30 / 2015)$. During this period, $R_{n}$ was also determined by a high precision sensor (net radiometer NR-Lite of Kipp \& Zonen ${ }^{\circledR}$ ).

$R_{n}$ obtained by estimates of both methods from measurements of $R_{s}$ was compared against the measurements of $R_{n}$, using as analysis criteria linear regression. In addition, estimates were evaluated by methods of simple agreements analysis between modeled and measured values (mean error "ME", root mean squared error "RMSE", mean absolute error "MAE" and relative mean absolute error "RMAE"). Normalized methods were also used (modeling efficiency "EF", Pearson correlation coefficient " $r$ ", and Willmott agreement index "d"). Finally, a last analysis was performed by a method based on the adoption of a limited value (percentage of errors lower than the limited established "PELLE", assuming a maximum error of $10 \%)$. All analyses were implemented as disposed in Wallach et al. (2006).

\section{RESULTS AND DISCUSSION}

Gauss Method was satisfactorily calibrated as shown by high coefficient of determination $\left(\mathrm{R}^{2}=0.9171\right)$, low standard error $( \pm 1.8721 \%)$ and graphical adjustment (Figure 2). There can be noted that the relation $R_{n} / R_{s}$ varies over the year, being higher during months with higher temperature and more rain, summer (graphic extremes), and lower during the months of lower temperatures and less rain, winter (center of the graph).

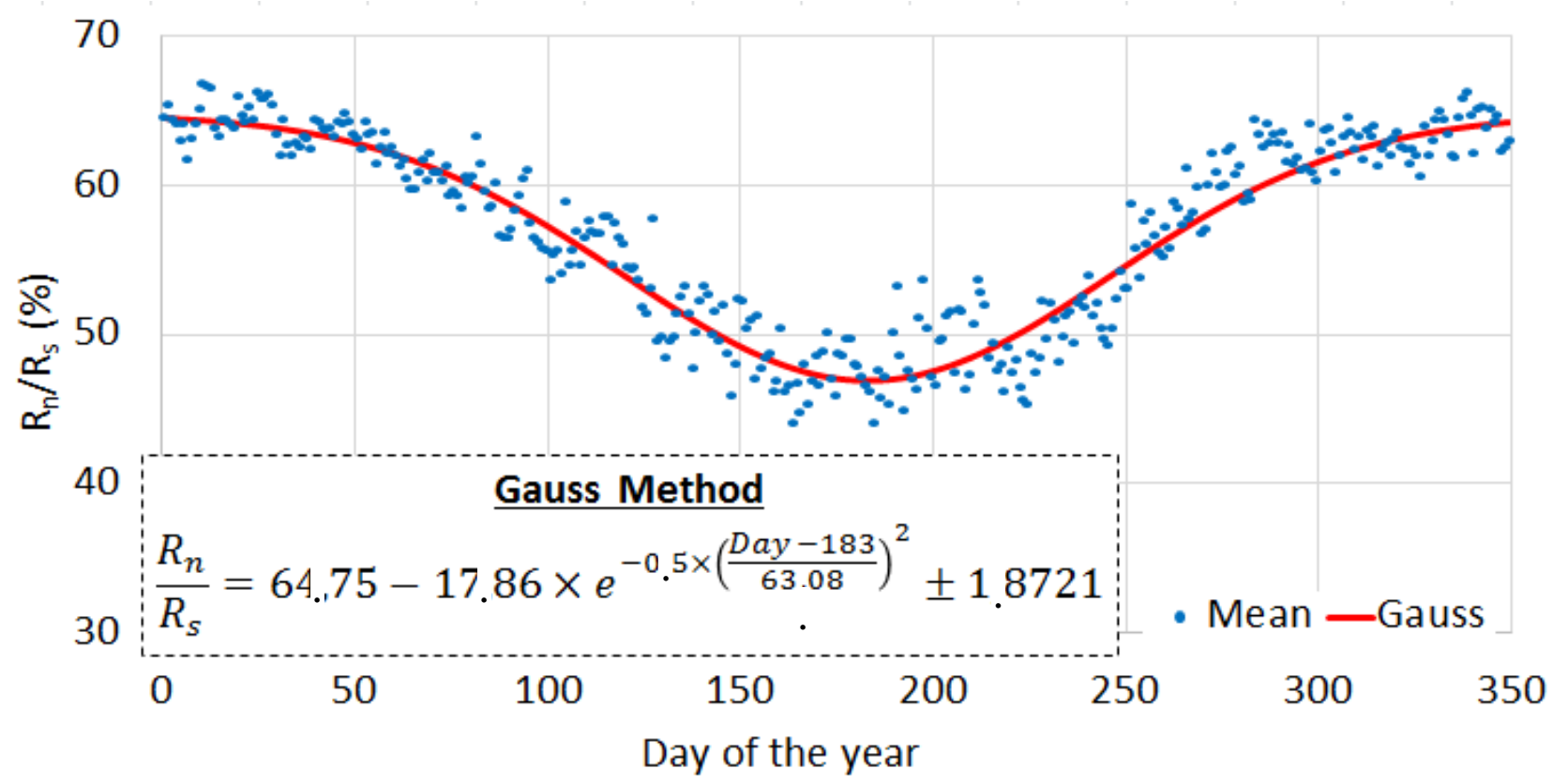

FIGURE 2. Adjustment of Gauss Method for determination of $R_{n} / R_{s}$ (net radiation/solar radiation) daily values, for the region of Dourados, State of Mato Grosso do Sul, Brazil. 
Considering the calibration of the Practical Method the mean annual relation $\mathrm{R}_{\mathrm{n}} / \mathrm{R}_{\mathrm{s}}$ is $57 \%$. From October to March this relation is higher than the annual mean, while from April to September is lower (Table 1). The highest $\mathrm{R}_{\mathrm{n}} / \mathrm{R}_{\mathrm{s}}$ is observed in January $(64.4 \%)$ and the lowest one in June $(47.7 \%)$, showing a difference between these extremes of $16.7 \%$. The values presented in Table 1 constitute the monthly adjustment coefficients of the Practical Method.

TABLE 1. Average monthly values of the relation $R_{n} / R_{s}$ (net radiation/solar radiation) for Dourados region, State of Mato Grosso do Sul, Brazil, accordingly to the Practical Method.

\begin{tabular}{cc}
\hline Month & Relation $\mathrm{R}_{\mathrm{n}} / \mathrm{R}_{\mathrm{s}}(\%)$ \\
\hline January & 64.4 \\
February & 63.1 \\
March & 60 \\
April & 56.5 \\
May & 51.2 \\
June & 47.7 \\
July & 48.4 \\
August & 49.5 \\
September & 55.8 \\
October & 61.7 \\
November & 62.7 \\
December & 63.9 \\
Annual (Mean) & 57
\end{tabular}

In a similar study conducted in the northwest region of São Paulo State, Brazil, Conceição (2006) found mean annual value of $65.3 \%$ for the relation $R_{n} / R_{s}$, being this higher than the mean value observed in the present study $(57 \%)$. Besides, the value found by Conceição (2006) exceeds even the maximum monthly value of the present study, which was observed in January (64.4\%). Although there is no mention provided by the author, the difference might be due to the fact that only positive $R_{n}$ values were used, neglecting the negative ones, what certainly result in higher $R_{n} / R_{s}$ ratio, as demonstrated by Sentelhas \& Nascimento (2003). Another important observation regarding Conceição (2006) is that the author presents a fixed relation to be used during the entire year, what might produce less accurate estimates, considering that the present study demonstrated a real necessity of recognize the variability of the relation $R_{n} / R_{s}$ during the year (Figure 2 and Table 1).

Pereira et al. (2007) recommended for the region of Piracicaba, São Paulo, Brazil, that values of $R_{n}$ can be predicted from measurements of $R_{s}$ by considering $R_{n}$ as a fraction of $57.4 \%$ of $R_{s}$. This value is very close to the observed in the present study (57\%). However, we still recommend the importance of recognizing the variability of this relation during the year. Silva et al. (2007) as well as Pereira et al. (2007) also obtained values (53\%) for the relation $\mathrm{R}_{\mathrm{n}} / \mathrm{R}_{\mathrm{s}}$ of Paspalum notatum Flügge close to that obtained in the present study.

During the two years of the validation the modeled trend for both methods followed the measured relation $\mathrm{R}_{\mathrm{n}} / \mathrm{R}_{\mathrm{s}}$, showing lower values during the winter and higher in the summer (Figure 3). However, there can be observed during the summer the modeled relation seems to be slightly and systematically higher as compared to the measured.

When analyzing the entirety of the data obtained during the validation years, there can be noted that both estimate methods showed performance considered satisfactory for estimating $R_{n}$ from $R_{s}$. This is evidenced by a good agreement between the data pair to the 1:1 line, showing high $\mathrm{R}^{2}$ values and slopes close to 1 (Figure 4 ).

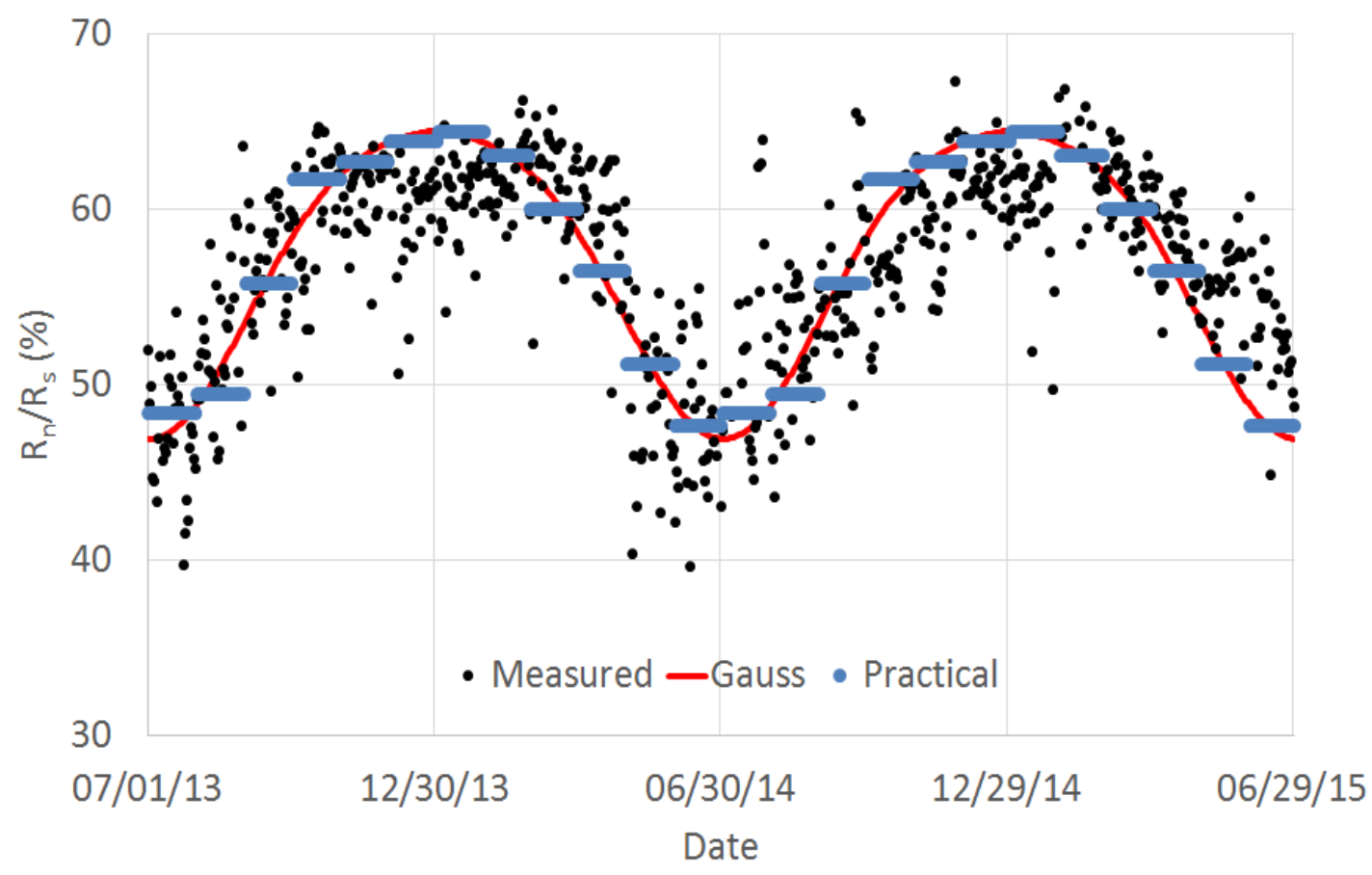

FIGURE 3. Measured $\mathrm{R}_{\mathrm{n}} / \mathrm{R}_{\mathrm{s}}$ (net radiation/solar radiation) values for the region of Dourados, State of Mato Grosso do Sul, Brazil, during the models validation period (07/01/2013 to 06/30/2015) and its comparison against the values parameterized for the Gauss and Practical Methods. 


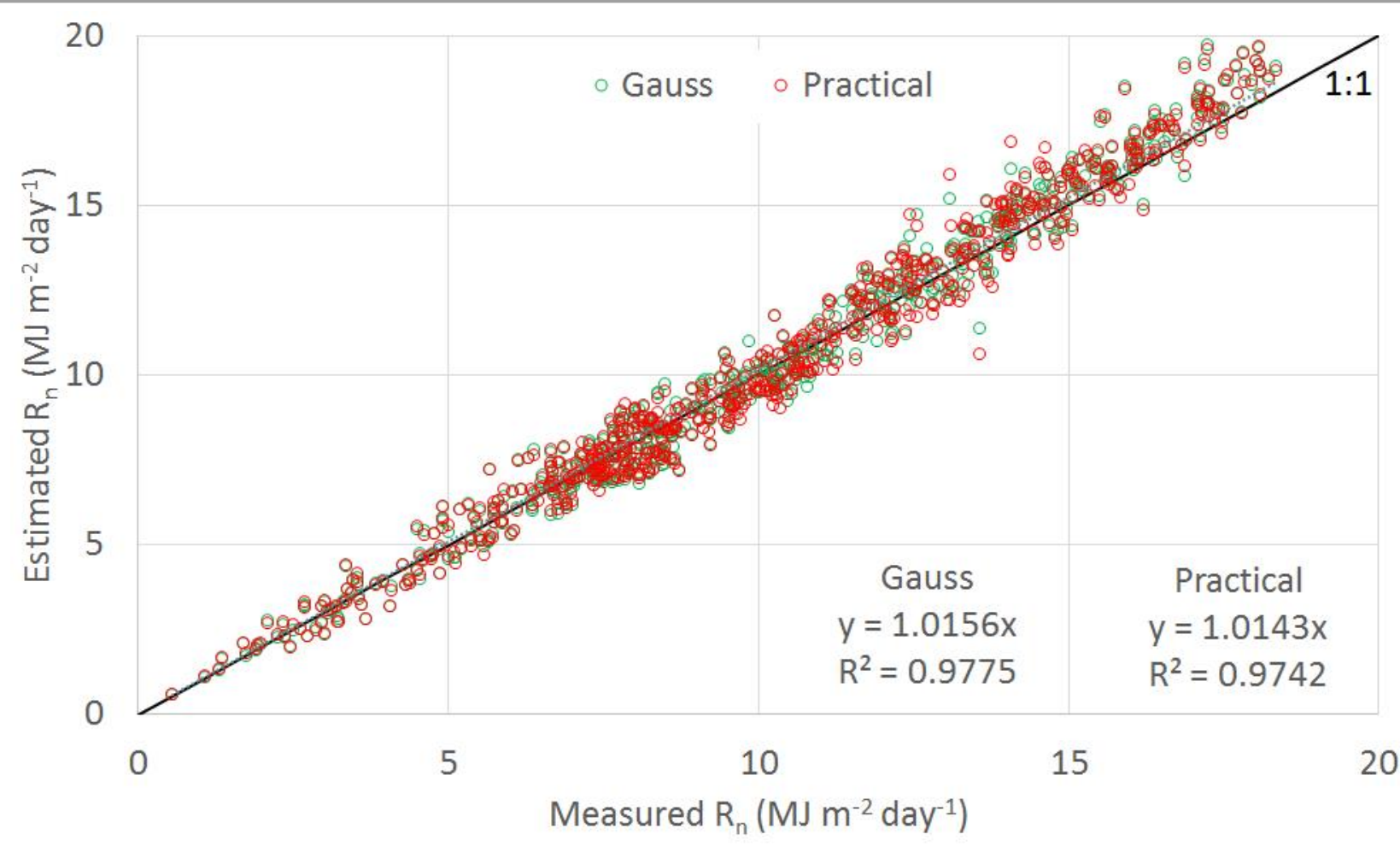

FIGURE 4. Linear regression analysis comparing $R_{n}$ (net radiation) estimated by the Gauss and Practical Methods from $R_{s}$ (solar radiation) against measured $R_{n}$ values during the validation period (07/01/2013 to 06/30/2015) at Dourados, State of Mato Grosso do Sul, Brazil.

Other statistics used to compare the Gauss and Practical Methods demonstrated adequate and similar performance between then, with a slightly advantage for Gauss Method (Table 2).

TABLE 2. Validation of the Gauss and Practical Methods for estimating $\mathrm{R}_{\mathrm{n}}$ (net radiation) from $\mathrm{R}_{\mathrm{s}}$ (solar radiation) measurements. The validation consisted in the agreement analysis between values estimated by both methods against the measured ones.

\begin{tabular}{|c|c|c|}
\hline Analysis index & Gauss & Practical \\
\hline ME $\left(\mathrm{MJ} \mathrm{m}^{-2}\right.$ day $\left.^{-1}\right)$ & -0.104 & -0.095 \\
\hline $\operatorname{RMSE}\left(\mathrm{MJ} \mathrm{m} \mathrm{m}^{-2} \mathrm{day}^{-1}\right)$ & 0.66 & 0.7 \\
\hline $\operatorname{MAE}\left(\mathrm{MJ} \mathrm{m}^{-2} \mathrm{day}^{-1}\right)$ & 0.53 & 0.55 \\
\hline RMAE $(\%)$ & 5.6 & 5.8 \\
\hline EF (dimensionless) & 0.97 & 0.97 \\
\hline r (dimensionless) & 0.99 & 0.99 \\
\hline $\mathrm{d}$ (dimensionless) & 0.99 & 0.99 \\
\hline PELLE (\%) & 85.2 & 83.5 \\
\hline
\end{tabular}

ME: mean error; RMSE: root mean squared error; MAE: mean absolute error; RMAE: relative mean absolute error; EF: modeling efficiency; r: Pearson correlation coefficient; $d$ : Willmott agreement index; PELLE: percentage of errors lower than the limited established (assuming a maximum error of $10 \%$ ).

The statistics of simple agreements analysis between modeled and measured values demonstrated results with a slightly advantage for the Gauss Method, considering the lower RMSE, MAE and RMAE. The exception was ME, which was closer to 0 in the Practical Method. Negative ME reveals a trend of both methods in overestimate the $R_{n}$. However, this overestimation is small, remaining close to $0.1 \mathrm{MJ} \mathrm{m}^{-2}$ day $^{-1}$. Nevertheless, as pointed out by Wallach et al. (2006), analyze only ME is not adequate to explain the extent of the errors, because they can be originated from small errors that cancels each other, or they can be big errors that also cancels each other. Therefore, analyzing MAE and RMAE helps when demonstrate the real extent of these errors. In this way, the MAE is 0.53 and $0.55 \mathrm{MJ} \mathrm{m}^{-2}$ day $^{-1}$ for the Gauss and Practical Methods, respectively, resulting in errors that are really small and equals 5.6 and $5.8 \%$, respectively.

With respect to the normalized methods of analysis $(\mathrm{EF}, \mathrm{r}$ and $\mathrm{d})$, results demonstrate high quality of both methods (values close to 1) and also their similarity (equal values for both methods). However, when analyzing PELLE statistic, which is centered on the acceptance of errors contained in a pre-established limit, it was observed a small advantage of the Gauss Method, considering that $85.2 \%$ of the estimates by this method produced errors lower than $10 \%$ (accepted limit). For the Practical Method the result was slightly worst, because $83.5 \%$ of the estimates were within the pre-established limit.

\section{CONCLUSIONS}

For Dourados City, located in the State of Mato Grosso do Sul, Brazil, both adjusted methods are adequate for estimating $R_{n}$ from $R_{s}$ measurements. These authors would like to recommend the use of the Gauss Method, especially in more rigorous applications, where care concerning the estimated value is more pronounced. On the other hand, for ordinary applications, with less rigidity, we recommend the use of the Practical Method, due to its easier calculation.

Although both methods were empirically set to be used in the studied region, these authors presumes that they are also valid for other regions that have similar climatic and latitude conditions, such as other regions in the States of Mato Grosso do Sul, Paraná, São Paulo, and even maybe in Paraguay. 


\section{REFERENCES}

Allen RG (1996) Assessing integrity of weather data for reference evapotranspiration estimation. Journal of Irrigation and Drainage Engineering 122(2):97-106.

Allen RG, Pereira LS, Raes D, Smith M (1998) Crop evapotranspiration: guidelines for computing crop water requirements. Rome, FAO. 300p. (FAO Irrigation and Drainage Paper, 56).

Allen RG, Walter IA, Elliott RL, Howell TA, Itenfisu D, Jensen ME, Snyder RL (2005) The ASCE standardized reference evapotranspiration equation. Reston, American Society of Civil Engineers, Environmental and Water Resources Institute, 216p.

Bisht G, Bras RL (2010) Estimation of net radiation from the MODIS data under all sky conditions: Southern Great Plains case study. Remote Sensing of Environment 114(7):1522-1534.

Bisht G, Venturini V, Islam S, Jiang L (2005) Estimation of the net radiation using MODIS (Moderate Resolution Imaging Spectroradiometer) data for clear-sky days. Remote Sensing of Environment 97(1):52-67.

Conceição MAF (2006) Estimativa do saldo de radiação no noroeste paulista com base na radiação solar incidente. Embrapa Uva e Vinho. 2p. (Comunicado Técnico, 69).

EMBRAPA. Guia clima. Available: http://www.cpao.embrapa.br/clima. Accessed: Aug 1, 2014.

Fietz CR, Fisch GF (2008) O clima na região de Dourados, MS. Embrapa Agropecuária Oeste. 32p. (Documentos, 92).
Heldwein AB, Maldaner IC, Bosco LC, Trentin G, Grimm EL, Radons SZ, Pitol Lucas DD (2012) Saldo de radiação diurno em dosséis de batata como função da radiação solar global. Revista Ciência Agronômica 3(1):96-104.

Kottek M, Grieser J, Beck C, Rudolf B, Rubel F (2006) World map of the Köppen-Geiger climate classification updated. Meteorologische Zeitschrift 15(3):259-263.

Pereira RA, Angelocci LR, Sentelhas PC (2007) Meteorologia agrícola. Piracicaba, ESALQ/USP. 192p.

Santos FAC, Santos CAC, Silva BB, Araújo AL, Cunha JEBL (2015) Desempenho de metodologias para estimativa do saldo de radiação a partir de imagens modis. Revista Brasileira de Meteorologia 30(3):295-306.

Sentelhas PC, Nascimento ALC (2003) Variação sazonal da relação entre o saldo de radiação e a irradiância solar global. Revista Brasileira de Meteorologia 18(1):71-77.

Silva LDB, Folegatti MV, Villa Nova NA, Carvalho DF (2007) Relações do saldo de radiação em grama batatais e capim tanzânia com a radiação solar global em Piracicaba, SP. Revista Brasileira de Agrometeorologia 15(3):250256.

Wallach D, Makowski D, Jones JW (2006) Working with dynamic crop models: evaluation, analysis, parameterization, and applications. Amsterdam, Elsevier. $447 p$. 